\title{
Intussusception Caused by a Colonic Solitary Fibrous Tumor
}

\author{
Mafalda Sousa $^{a}$ Luísa Proença $^{a}$ Helena Baldaia $^{b}$ \\ ${ }^{a}$ Gastroenterology Department, Centro Hospitalar de Vila Nova de Gaia e Espinho, Vila Nova de Gaia, Portugal; \\ ${ }^{b}$ LAP, Unilabs, Porto, Portugal
}

Keywords

Cancer $\cdot$ Intussusception $\cdot$ Solitary fibrous tumor

\section{Invaginação por tumor fibroso solitário do cólon \\ Palavras-chave \\ Cancro · Invaginação · Tumor fibroso solitário}

A 65-year-old male patient was admitted to the emergency department for right iliac fossa pain and hematochezia. Physical examination showed a palpable mass in the right iliac fossa. Laboratory tests showed anemia (10.3 $\mathrm{g} / \mathrm{dL})$ and an elevated CRP level $(6.40 \mathrm{mg} / \mathrm{dL})$. Abdominal ultrasound revealed an irregular thickening of the cecum with a heterogeneous expansive lesion of $9 \times 5 \times$ $6 \mathrm{~cm}$ (Fig. 1). The patient underwent colonoscopy which showed an ileocolic intussusception caused by a necrotic mass in the ascending colon and cecum (Fig. 2).

The patient was submitted to urgent right hemicolectomy with ileocolic anastomosis. The histology of the operative specimen revealed a fibroblastic spindle cell lesion of $6 \times 8 \mathrm{~cm}$ with cellular atypia, low mitotic index, without

\section{KARGER}

E-Mail karger@karger.com www.karger.com/pjg
(C) 2019 Sociedade Portuguesa de Gastrenterologia Published by S. Karger AG, Basel

Karcer

Open access

This article is licensed under the Creative Commons AttributionNonCommercial-NoDerivatives 4.0 International License (CC BYNC-ND) (http://www.karger.com/Services/OpenAccessLicense). Usage and distribution for commercial purposes as well as any distribution of modified material requires written permission. necrosis, hemorrhage, lymphatic or vascular invasion. (Fig. 3a) The lesion was centered in the muscularis propria and serosa of the cecum and the ileocecal appendix, with colonic and ileal margins free from disease. Immunohistochemical characteristics were compatible with solitary fibrous tumor (positive vimentin, diffuse nuclear and cytoplasmatic immunoreactivity for STAT6 and negative C-KIT, DOG-1, CD34, S100, CAM 5.2, CD31, EMA, actin, and desmin) (Fig. 3b). The patient showed no disease recurrence after 10 months of follow-up.

Solitary fibrous tumors are rare tumors of mesenchymal origin and can occur at any age and any site [1]. The most commonly affected places are the pleura, peritoneum, meninges, and lower extremities, but they can also be found in any other part of the body including the mesentery as in our patient $[1,2]$. Clinical manifestations are highly variable according to the location of the tumor, but patients often present with a painless mass or pressure effect depending on the anatomy and size of the tumor.

It can be difficult to distinguish solitary fibrous tumors from other benign mesenchymal tumors and sarcomas, especially when they arise in extrathoracic sites [3]. STAT6 is a highly sensitive and almost perfectly specific immunohistochemical marker and can be helpful when diagnosis is inconclusive [3]. The presence of $>4$ mitotic 

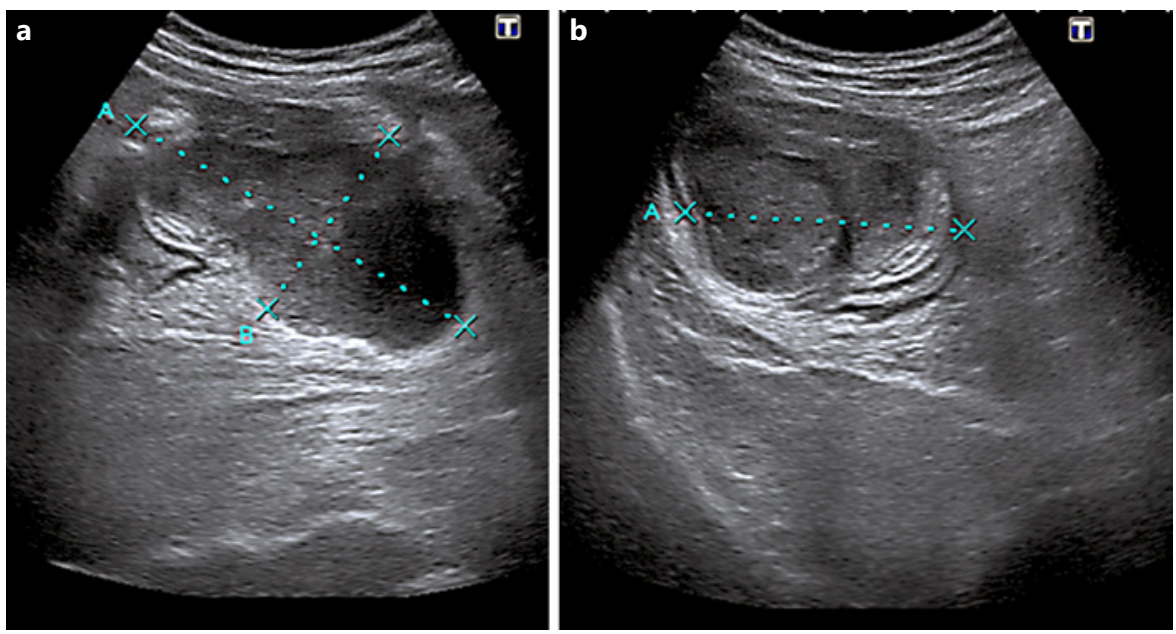

Fig. 1. Ultrasound revealed an irregular thickening of the cecum with a heterogeneous expansive lesion.



Fig. 2. Necrotic mass in the ascending colon and cecum.
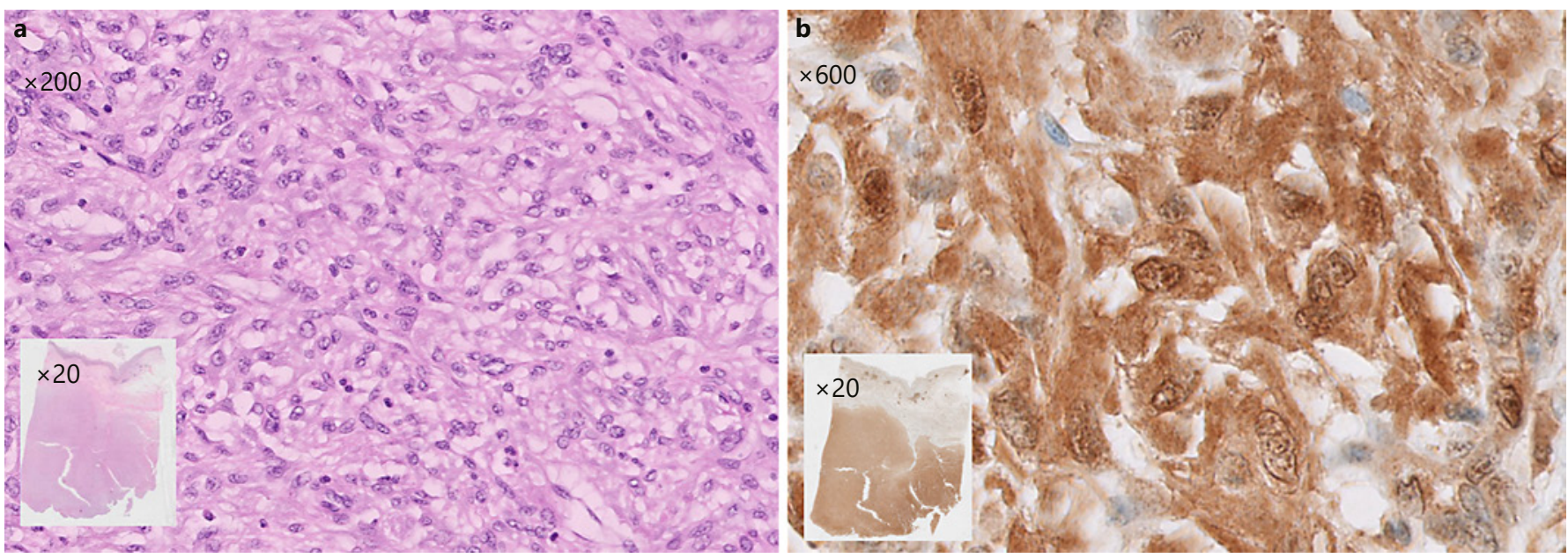

Fig. 3. Fibroblastic spindle cell lesion with diffuse nuclear and cytoplasmatic immunoreactivity with STAT6.

figures per 10 high-power fields, the presence of necrosis and/or hemorrhage, hypercellularity, cellular atypia, nuclear pleomorphism, and/or stromal or vascular invasion are suggestive of malignant disease [4].

Treatment is based on surgical excision of both benign and malignant disease; radiotherapy may be used for preoperative tumor shrinkage and/or as adjuvant therapy in patients with malignant disease or incomplete surgical margins [4].

The prognosis for extrathoracic solitary fibrous tumor can be unpredictable [5]. The presence of malignant pathologic features, tumor origin in the abdomen or pelvis, large tumor size, incomplete surgical resection mar- gins, and dedifferentiation are associated with an increased risk of disease recurrence and reduced survival [4].

\section{Statement of Ethics}

Informed patient consent was obtained for the publication of the case details.

\section{Disclosure Statement}

The authors report no financial support or competing interests.
60

GE Port J Gastroenterol 2020;27:59-61 DOI: $10.1159 / 000499137$
Sousa/Proença/Baldaia 
References
1 DeVito N, Henderson E, Han G, Reed D, Bui MM, Lavey R, et al. Clinical Characteristics and Outcomes for Solitary Fibrous Tumor (SFT): A Single Center Experience. PLoS One. 2015 Oct;10(10):e0140362.

2 Nishida K, Ubukata H, Konishi S, Shimazaki J, Yano Y, Morishita Y, et al. A giant solitary fibrous tumor of the mesentery: a case report and literature review. World J Surg Oncol. 2015 Feb;13(1):17.

3 Yoshida A, Tsuta K, Ohno M, Yoshida M, Narita Y, Kawai A, et al. STAT6 immunohis- tochemistry is helpful in the diagnosis of solitary fibrous tumors. Am J Surg Pathol. 2014 Apr;38(4):552-9.

4 Kayani B, Sharma A, Sewell MD, Platinum J, Olivier A, Briggs TW, et al. A Review of the Surgical Management of Extrathoracic Solitary Fibrous Tumors. Am J Clin Oncol. 2018 Jul;41(7):687-94.

5 Cranshaw IM, Gikas PD, Fisher C, Thway K, Thomas JM, Hayes AJ. Clinical outcomes of extra-thoracic solitary fibrous tumours. Eur J Surg Oncol. 2009 Sep;35(9):994-8. 